\title{
Multiple culprit lesions in ST-segment elevation myocardial infarction with cardiogenic shock: a case of simultaneous thrombosis of two infarct-related arteries
}

\author{
R. Caliskan $\cdot$ H. Ince $\cdot$ F. Arslan (D)
}

Accepted: 12 January 2022 / Published online: 24 February 2022

(C) The Author(s) 2022

A 64-year-old male with previous primary percutaneous coronary intervention (pPCI) of the left anterior descending artery (LAD) presented with cardiogenic shock and inferior wall ST-segment elevation myocardial infarction (STEMI) (Fig. 1a). Coronary angiography revealed an in-stent $\mathrm{LAD}$ occlusion with little contrast stasis (Fig. 1a) and stenosis of the circumflex coronary artery (RCx) with poorly perfused collaterals to the right coronary artery (RCA) and LAD. After pPCI of the RCA (Fig. 1b), chest pain persisted without ST-segment resolution. Therefore, we decided to revascularise the $\mathrm{LAD}$ on the assumption that it contained fresh thrombus. After easy wiring and pPCI of the LAD, the patient's complaints and the ST segments resolved with haemodynamic recovery (Fig. 1b). The large, patent first septal branch may have been the reason for the absence of electrocardiographic signs of anterior wall infarction [1]. Multiple culprit vessels are rare in STEMI and associated with cardiogenic shock and high mortality [2, 3]. Further diagnostic studies were negative for hypercoagulability or paradoxical emboli [4]. Being mindful of complaints and electrocardiographic changes may help to guide invasive management of STEMI patients with complicated anatomy.

\author{
R. Caliskan $\cdot$ H. Ince $\cdot$ F. Arslan $(\varangle)$ \\ Department of Cardiology, Vivantes Klinikum am Urban, \\ Berlin, Germany \\ fatih.arslan@vivantes.de \\ H. Ince \\ Department of Cardiology, Rostock University Medical \\ Centre, Rostock, Germany
}

Conflict of interest R. Caliskan, H. Ince and F. Arslan declare that they have no competing interests.

Open Access This article is licensed under a Creative Commons Attribution 4.0 International License, which permits use, sharing, adaptation, distribution and reproduction in any medium or format, as long as you give appropriate credit to the original author(s) and the source, provide a link to the Creative Commons licence, and indicate if changes were made. The images or other third party material in this article are included in the article's Creative Commons licence, unless indicated otherwise in a credit line to the material. If material is not included in the article's Creative Commons licence and your intended use is not permitted by statutory regulation or exceeds the permitted use, you will need to obtain permission directly from the copyright holder. To view a copy of this licence, visit http://creativecommons.org/licenses/by/4.0/.

\section{References}

1. Wagner GS, Macfarlane P, Wellens H, et al. AHA/ACCF/HRS recommendations for the standardization and interpretation of the electrocardiogram: part VI: acute ischemia/ infarction: a scientific statement from the American Heart Association Electrocardiography and Arrhythmias Committee, Council on Clinical Cardiology; the American College of Cardiology Foundation; and the Heart Rhythm Society. Endorsed by the International Society for Computerized Electrocardiology. JAm Coll Cardiol. 2009;53:1003-11.

2. Kuzemczak M, Kasinowski R, Skrobich P, Podlewski R, Kalmucki P. A successfully treated STEMI due to simultaneous thrombotic occlusion of left anterior descending artery and left circumflex artery: a case report and review of the literature. Cardiol Res. 2018;9:395-9.

3. Goldstein JA, Demetriou D, Grines CL, Pica M, Shoukfeh M, O'Neill WW. Multiple complex coronary plaques in patients with acute myocardial infarction. $\mathrm{N}$ Engl J Med. 2000;343:915-22.

4. Kanei Y, Janardhanan R, Fox JT, Gowda RM. Multivessel coronary artery thrombosis. J Invasive Cardiol. 2009;21:66-8. 


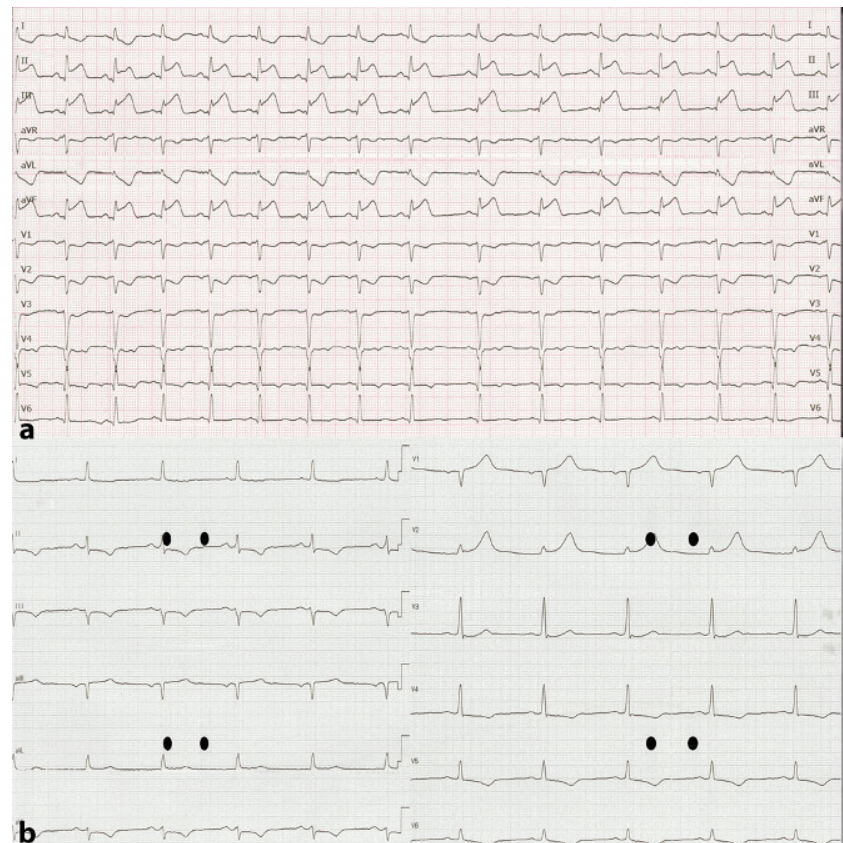

Fig. 1 a, b Electrocardiography (ECG) and angiography of coronary arteries before and after primary percutaneous coronary intervention. a ECG at presentation with signs of acute inferior wall myocardial infarction. Diagnostic angiography revealing occlusions of both the proximal right coronary artery

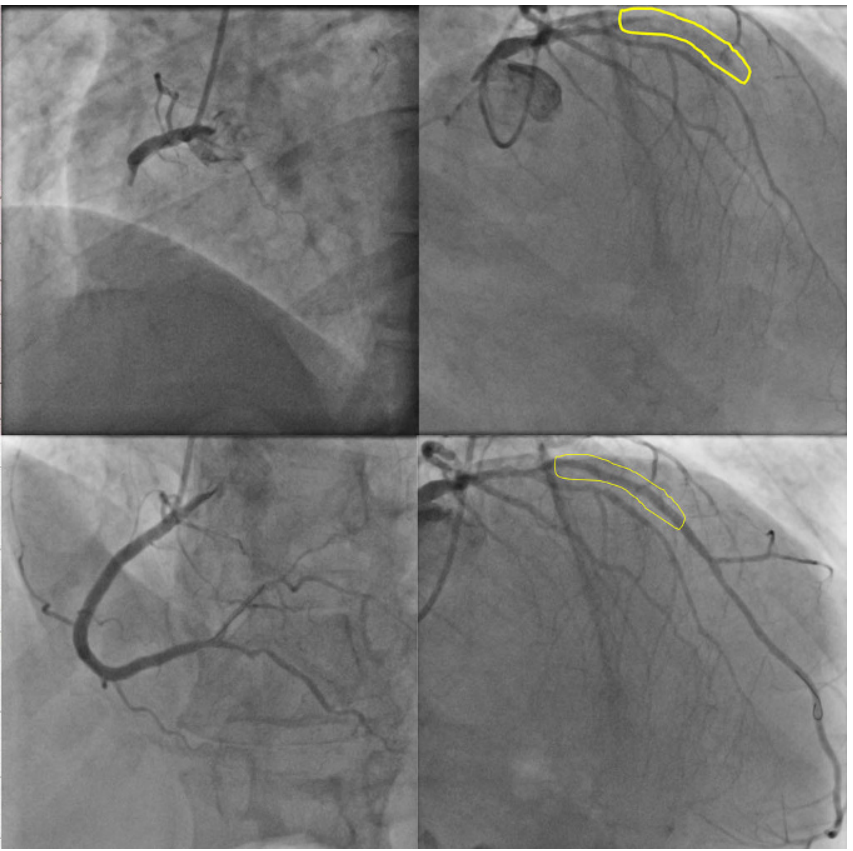

(RCA, left panel) and left anterior descending artery (LAD) after S1 (right panel; lesion site highlighted in yellow). b Post-procedural ECG showing ST-segment resolution after successful revascularisation of the RCA (left panel) and LAD (right panel) 